\title{
GIS-based high-resolution spatial interpolation of precipitation in mountain-plain areas of Upper Pakistan for regional climate change impact studies
}

\author{
Muhammad Waseem Ashiq • Chuanyan Zhao • \\ Jian Ni • Muhammad Akhtar
}

Received: 4 July 2008 / Accepted: 14 April 2009/Published online: 5 May 2009

(C) Springer-Verlag 2009

\begin{abstract}
In this study, the baseline period (1960-1990) precipitation simulation of regional climate model PRECIS is evaluated and downscaled on a monthly basis for northwestern Himalayan mountains and upper Indus plains of Pakistan. Different interpolation models in GIS environment are used to generate fine scale $\left(250 \times 250 \mathrm{~m}^{2}\right)$ precipitation surfaces from PRECIS precipitation data. Results show that the multivariate extension model of
\end{abstract}

\footnotetext{
M. W. Ashiq $(\bowtie)$

Punjab Forest Department,

Lahore, Pakistan

e-mail: waseempfd@yahoo.com

M. W. Ashiq · M. Akhtar

Institute of Geology, University of the Punjab (PU),

Lahore, Pakistan

C. Zhao

Key Laboratory of Arid and Grassland Agroecology

of Ministry of Education, Lanzhou University,

Lanzhou, China

J. Ni

Max Planck Institute for Biogeochemistry,

Jena, Germany

Present Address:

J. Ni

Alfred Wegener Institute for Polar and Marine Research,

Potsdam, Germany

Present Address:

M. W. Ashiq

Centre for Forest Conservation Genetics,

Department of Forest Sciences,

University of British Columbia (UBC),

Vancouver, Canada
}

ordinary kriging that uses elevation as secondary data is the best model especially for monsoon months. Model results are further compared with observations from 25 meteorological stations in the study area. Modeled data show overall good correlation with observations confirming the ability of PRECIS to capture major precipitation features in the region. Results for low and erratic precipitation months, September and October, are however showing poor correlation with observations. During monsoon months (June, July, August) precipitation pattern is different from the rest of the months. It increases from south to north, but during monsoon maximum precipitation is in the southern regions of the Himalayas, and extreme northern areas receive very less precipitation. Modeled precipitation toward the end of the twenty-first century under A2 and B2 scenarios show overall decrease during winter and increase in spring and monsoon in the study area. Spatially, both scenarios show similar pattern but with varying magnitude. In monsoon, the Himalayan southern regions will have more precipitation, whereas northern areas and southern plains will face decrease in precipitation. Western and south western areas will suffer from less precipitation throughout the year except peak monsoon months. $T$ test results also show that changes in monthly precipitation over the study area are significant except for July, August, and December. Result of this study provide reliable basis for further climate change impact studies on various resources.

\section{Introduction}

The impact of climate change due to changes in the atmospheric greenhouse gas concentrations has serious 
implications for the management of resources and the sustainable development of the societies concerned. Though General Circulation Models (GCMs) provide good overview of the current climate and predict future climate changes at global level, their suitability for climate change impact assessment on various natural and managed systems at regional or local scale is questioned due to their course resolution (Grotch and MacCracken 1991; von Storch et al. 1993; Ciret and Sellers 1998; Hellström and Chen 2003; Gaffin et al. 2004; Linderson et al. 2004). Some crucial parameters like altitude that significantly contribute in determining climate are not fully captured in coarse resolution GCMs, as these can vary across very short distances. Downscaling of GCM outputs is therefore needed to get situation-specific information about climate and to further investigate the impacts in climate change situations (Li and Sailor 2000; van Vuuren et al. 2007). Downscaling, a technique to bridge the gap of GCM prediction skill over different scales is carried out by two distinct methods: (1) dynamical downscaling - by nesting high-resolution Regional Climate Models (RCM) with GCM (Giorgi 1990; Giorgi and Mearns 1991); and (2) statistical downscaling - by finding the relationship between observed large-scale and regional climate, and applying that to the GCM output (Karl et al. 1990). Details about theory and applications of these methods are well described in the literature (Murphy 1999; von Storch 1999; Xu 1999; Zorita and von Storch 1999; Yarnal et al. 2001; Linderson et al. 2004).

Among various climatic variables, precipitation is the one that is essentially required for a number of applications like natural resource management, agriculture management, irrigation scheduling, ecosystem modeling, and hydrological modeling. Understanding of its temporal and spatial distribution is also important for undertaking climate change impact studies on various systems (Busuioc et al. 2001). However, high degree of inherent variability due to regional and local atmospheric processes that is not fully captured by the GCM make it difficult to directly use the GCM output for further reliable application (Karl et al. 1990). Both downscaling methods (dynamical and statistical) have therefore been applied independently or in a hybrid (Charles et al. 1999; Fuentes and Heimann 2000; Hellström and Chen 2003) to improve the GCM output with a varying degree of results. Compared to statistical downscaling, nesting of the RCM within the GCM is supported due to the assumption that the large-scale climate is well simulated by the GCM, and further, finer resolution of RCM will better represent the near-surface small-scale variability (Hellström and Chen 2003). However, due to some uncertainty in the modeling, it is still necessary to assess RCM output with the present-day observed precipitation before further application. The method described for
GCM in Busuioc et al. (2001) can also be applied to RCM output by comparing it with the long-term mean of observed precipitation data over the study area. Again, the application of RCM output is limited in certain cases because of its resolution $\left(\sim 0.5^{\circ} \times 0.5^{\circ}\right)$ that requires further downscaling to a scale appropriate for a specific study. To enhance the ability to quantify effects of climate (and climate variability) and to forecast the possible impacts of climate change, a variety of interpolation algorithms are available (Price et al. 2000). The most common of these is Thiessen Polygon (Thiessen 1911) which has been widely applied to the interpolation of point measurements (Tabios and Salas 1985; Dirks et al. 1998). Recently, GIS-based interpolation techniques are also being widely used for the interpolation of point climatic variable data (observed or modeled). Agnew and Palutikof (2000) provide a good overview of such studies in Europe and Mediterranean. Lloyd (2005) compared the performance of five different interpolation methods and concludes that methods including elevation as secondary data perform better than others because of the relationship between precipitation and elevation. This relationship has already been reported by Brunsdon et al. (2001) with regional variations.

As there is lack of literature and reliable precipitation data for Pakistan to carry out landscape scale climate change impact assessments, the present study is designed with the objectives to: (1) validate the outputs of PRECIS (Providing REgional Climate for Impact Studies) RCM run for South Asia domain in terms of its ability to reproduce the observed precipitation patterns in the study area (2) compare various GIS-based interpolation techniques for interpolation of PRECIS modeled precipitation; and (3) generate fine-scale monthly precipitation data for the baseline period as well as IPCC A2 and B2 future scenarios for further use in climate change impact studies on various sectors especially forestry, agriculture, and hydrology.

\section{Study area}

Situated between $69^{\circ} 20^{\prime}-75^{\circ} 28^{\prime} \mathrm{E}$ and $27^{\circ} 52^{\prime}-35^{\circ} 42^{\prime} \mathrm{N}$, the landscape of the study area characterizes great diversity from biodiversity-rich Himalayan mountains in the north to flat agricultural plains of mighty Indus river system in the south. Elevation ranges from 61 to $6,126 \mathrm{~m}$ above sea level. In addition to hydrological functions and agricultural production, the area also plays important roles of ecological, social, and protective nature.

It is also one of the most populated areas in the region and administratively consists of Punjab Province, part of North Western Frontier Province (NWFP) and Azad Jammu and Kashmir (AJK) valley in Pakistan (Fig. 1). 


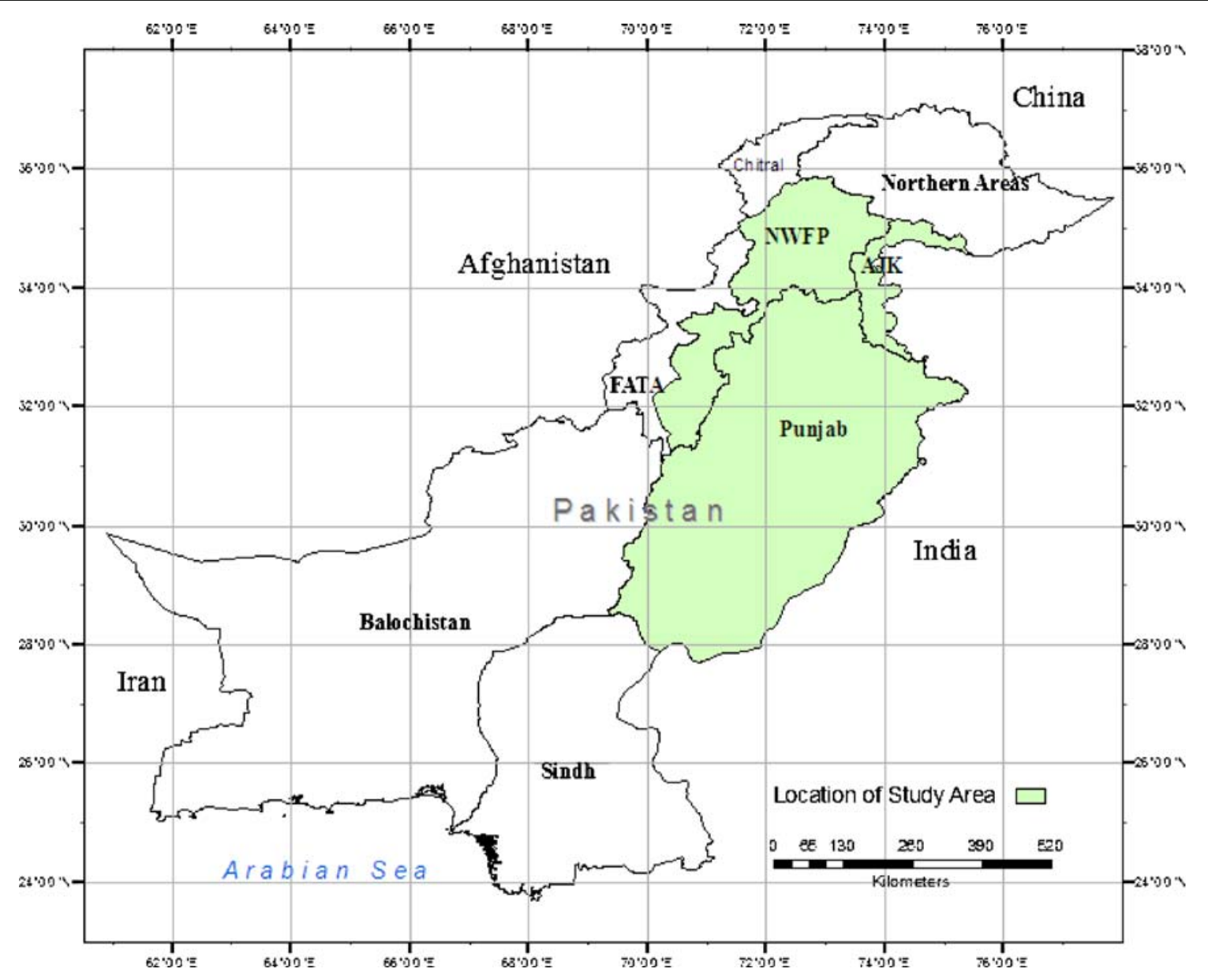

Fig. 1 Location of study area

\section{Data and methods}

Two sets of precipitation data (modeled and observational) are used in this study. Modeled precipitation data for the study area is obtained from a PRECIS run by Akhtar et al. (2008). PRECIS is a high-resolution atmospheric and land surface model that is forced at its lateral boundaries by the simulations of high-resolution $(150 \mathrm{~km} \times 150 \mathrm{~km})$ atmospheric component (HadAM3P atmosphere only GCM) of the HadCM3 coupled GCM model. For the baseline period (1961-1990), climate HadAM3P is driven with the observed sea surface temperature, and for future scenarios (2071-2100) sea surface temperature conditions are constructed by adding anomalies from a transient simulation of HadCM3 to observations (Gordon et al. 2000; Jones et al. 2003; Wilson et al. 2005). The atmospheric dynamics module of PRECIS is a hydrostatic version of the full primitive equations and uses horizontal and vertical coordinates. There are 19 vertical levels, the lowest at $825 \mathrm{hPa}$ and the highest at $0.5 \mathrm{hPa}$. To control the accumulation of noise and energy at the grid scale, horizontal diffusion is also applied. The land surface scheme employed in the PRECIS is Meteorological Office Surface Exchange Scheme (MOSES) that has shown good skill in land surface simulation (Bowling et al. 2003; Nijssen et al. 2003). The reader is referred to Wilson et al. (2005) for full details about PRECIS. The domain size of PRECIS simulation by Akhtar et al. (2008) is bounded by latitude $12^{\circ}-41^{\circ} \mathrm{N}$ and longitude $55^{\circ}-97^{\circ} \mathrm{E}$ (Fig. 2), and the horizontal resolution is $0.44^{\circ} \times 0.44^{\circ}(\sim 50 \mathrm{Km})$ in rotation coordinates. This domain size is assumed to be large enough to include relevant regional forcing and to allow full development of internal mesoscale circulation. It covers most of South Asian region including Pakistan, India, Afghanistan, and Tibetan Plateau. PRECIS simulations data, for baseline period (1961-1990) and 2080s (2071-2100) for two different IPCC regionally focused development scenarios A2 (priority to economic issues) and B2 (priority to environmental issues), is obtained in ASCII format for this study. This data is averaged for every month for further interpolation in GIS environment using ArcGIS 9.2 to generate monthly (averaged for 30 years) precipitation surfaces. Summary statistics of baseline period data is shown in Table 1. 


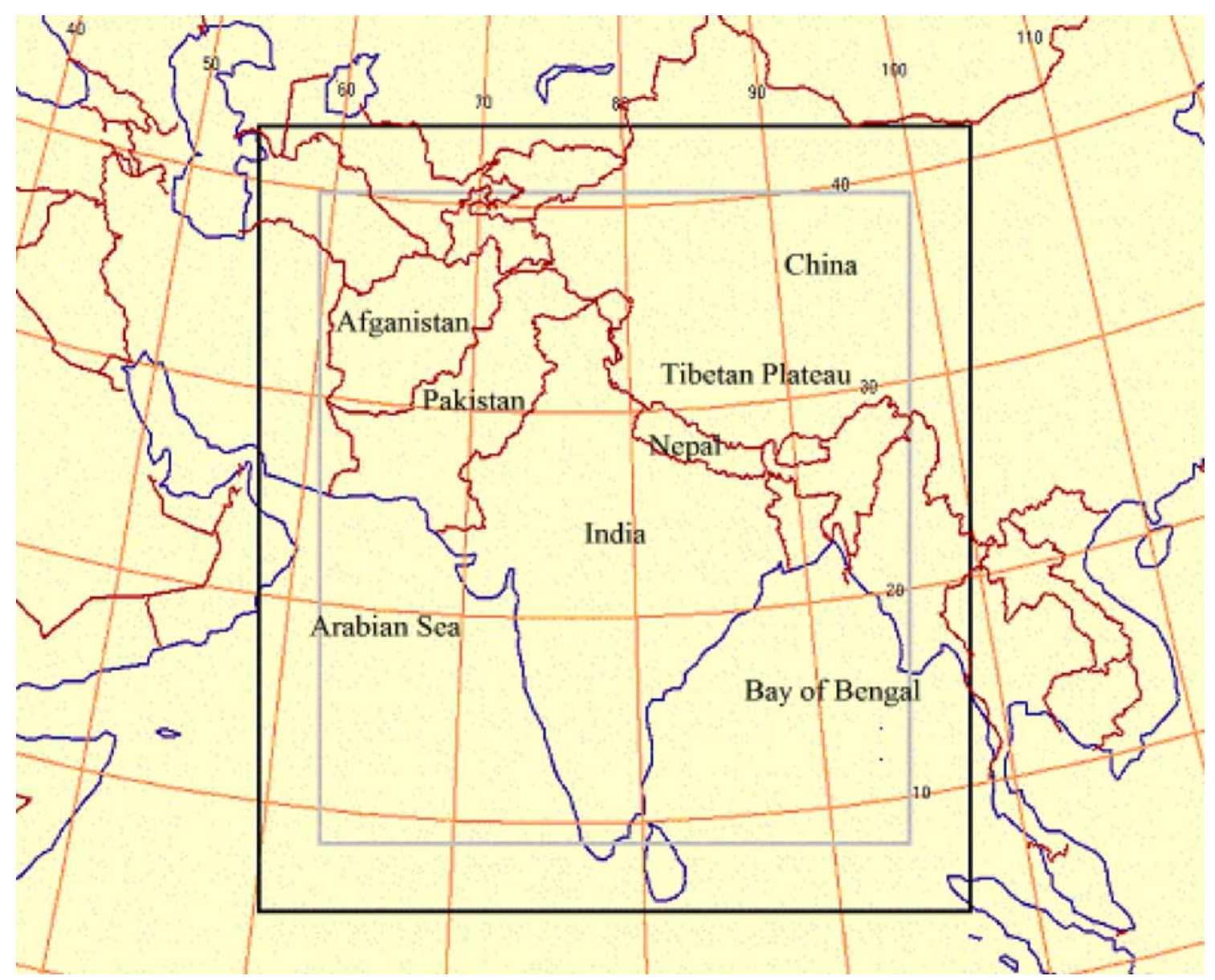

Fig. 2 Domain size of PRECIS simulation

Table 1 Summary Statistics of 30 years (1961-90) averaged PRECIS precipitation data in $\mathrm{mm} / \mathrm{month}$

\begin{tabular}{|c|c|c|c|c|c|c|c|c|}
\hline Month & Min & Max & Mean & SD & 1st Q & Median & 3rd Q & Q3-Q1 \\
\hline Jan & 0.5 & 207.0 & 27.8 & 38.4 & 2.8 & 8.9 & 42.3 & 39.5 \\
\hline Feb & 0.9 & 334.1 & 41.3 & 61.5 & 2.6 & 8.9 & 64.0 & 61.4 \\
\hline Mar & 0.7 & 374.9 & 52.2 & 81.6 & 2.7 & 9.6 & 73.3 & 70.6 \\
\hline Apr & 1.3 & 272.2 & 42.2 & 62.1 & 4.1 & 10.0 & 53.3 & 49.2 \\
\hline May & 1.2 & 118.9 & 23.1 & 27.2 & 5.3 & 11.7 & 28.1 & 22.8 \\
\hline Jun & 0.3 & 591.4 & 69.9 & 62.5 & 34.9 & 58.0 & 85.2 & 50.3 \\
\hline Jul & 0.0 & 638.3 & 142.8 & 93.1 & 105.7 & 135.1 & 166.2 & 60.5 \\
\hline Aug & 0.0 & 483.0 & 120.3 & 73.2 & 84.1 & 117.4 & 144.7 & 60.6 \\
\hline Sep & 0.0 & 327.2 & 81.9 & 45.2 & 58.8 & 78.5 & 99.9 & 41.1 \\
\hline Oct & 0.5 & 127.1 & 23.3 & 19.1 & 11.1 & 18.8 & 28.5 & 17.4 \\
\hline Nov & 1.7 & 159.2 & 27.9 & 34.4 & 5.6 & 10.8 & 39.8 & 34.2 \\
\hline Dec & 0.3 & 190.2 & 24.1 & 33.0 & 3.1 & 8.1 & 35.5 & 32.4 \\
\hline
\end{tabular}

$S D$ standard deviation which is a measure of statistical dispersion of precipitation data, $1 s t Q$ first quartile of precipitation data which is the value such the $25 \%$ of the values fall at or below this value, Median centre or midpoint value of the ordered precipitation data, $3 r d Q$ third quartile of precipitation data which is the value such the $75 \%$ of the values fall at or below this value, $Q 3-Q 1$ interquartile range and is a distance between 1 st and 3rd quartile 
Observational precipitation data is used to validate the results of the modeled data interpolation for baseline period. For this purpose, total monthly precipitation data of 25 Meteorological stations of Pakistan Meteorological Department is used. Location of observational stations is shown in Fig. 3. Out of these, data for 21 stations is available for the entire baseline period (1961-90), whereas records of precipitation for four stations, namely, Dir, Sadu Sharif, Rafiqui, and Bhawalnagar are available for shorter periods (Table 2). These stations are included to increase the coverage of the validation data points. Monthly data is averaged for the baseline/available period, and the basic

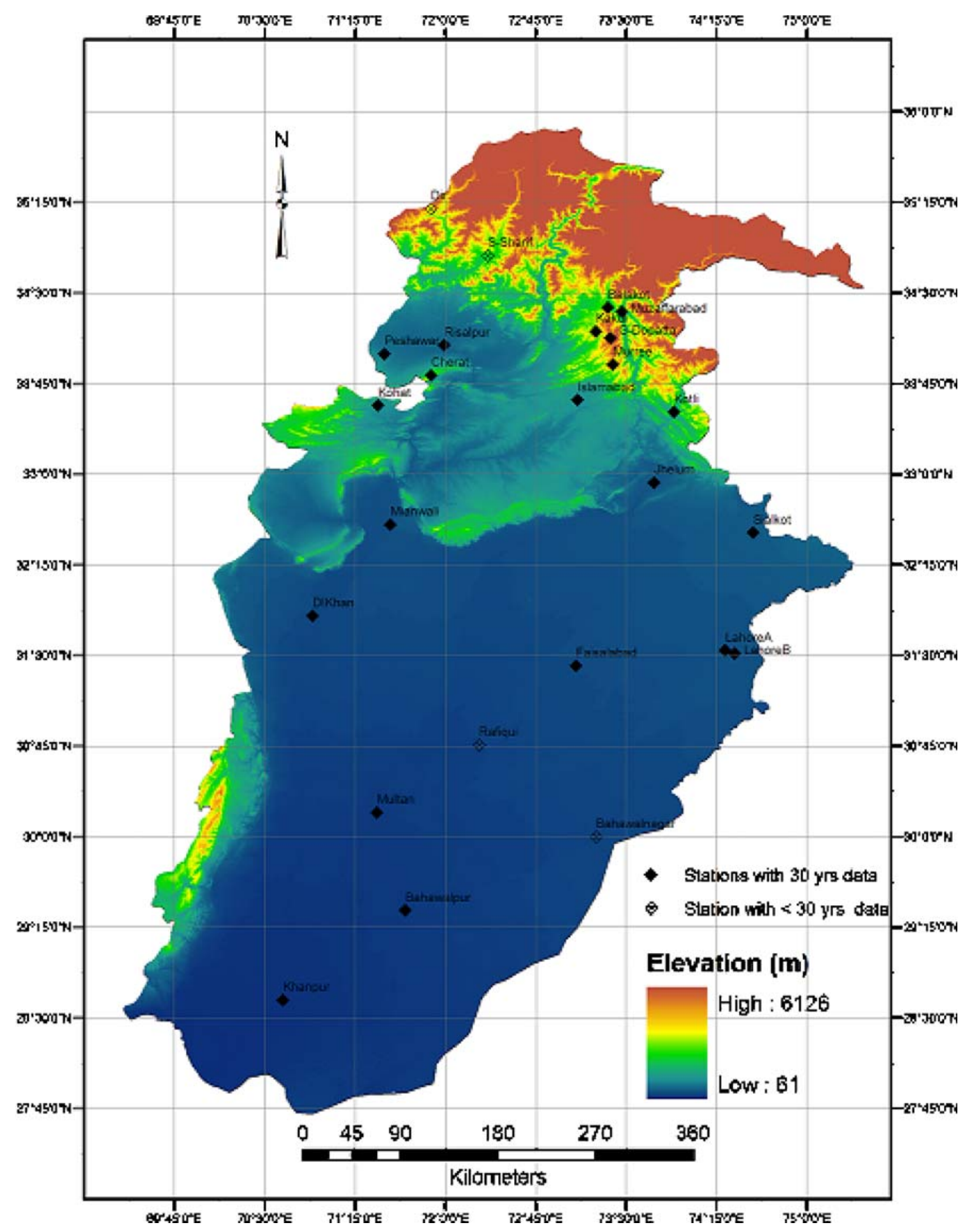

Fig. 3 Topography (DEM) of the study area and location of observational stations 
Table 2 Location and observation period of meteorological stations in the study area

\begin{tabular}{|c|c|c|c|c|c|}
\hline S. no. & Location & Latitude (dd) & Longitude (dd) & Altitude (m) & Period \\
\hline 1 & Dir & 35.19972 & 71.87977 & $1,375.0$ & 1967-1990 \\
\hline 2 & Sadu Sharif & 34.81336 & 72.35134 & 961.0 & 1974-1990 \\
\hline 3 & Balakot & 34.38000 & 73.35000 & 995.4 & $1961-1990$ \\
\hline 4 & Muzaffarabad & 34.35000 & 73.46707 & 838.0 & 1961-1990 \\
\hline 5 & Kakul & 34.18333 & 73.25000 & $1,308.0$ & 1961-1990 \\
\hline 6 & Garhi Dopatta & 34.13000 & 73.37000 & 813.5 & 1961-1990 \\
\hline 7 & Risalpur & 34.07000 & 71.99000 & 304.2 & 1961-1990 \\
\hline 8 & Peshawar & 33.99948 & 71.49618 & 328.8 & 1961-1990 \\
\hline 9 & Murree & 33.90972 & 73.39011 & $2,133.6$ & 1961-1990 \\
\hline 10 & Cherat & 33.82019 & 71.88439 & $1,372.0$ & $1961-1990$ \\
\hline 11 & Islamabad & 33.61599 & 73.09932 & 508.0 & 1961-1990 \\
\hline 12 & Kohat & 33.57027 & 71.43955 & 564.6 & 1961-1990 \\
\hline 13 & Kotli & 33.51713 & 73.89873 & 614.0 & 1961-1990 \\
\hline 14 & Jhelum & 32.93324 & 73.73354 & 287.2 & 1961-1990 \\
\hline 15 & Mianwali & 32.58503 & 71.54390 & 204.6 & 1961-1990 \\
\hline 16 & Sialkot & 32.51700 & 74.55512 & 255.1 & 1961-1990 \\
\hline 17 & DIKhan & 31.83000 & 70.90000 & 171.2 & 1961-1990 \\
\hline 18 & Lahore_A & 31.54260 & 74.32474 & 214.0 & 1961-1990 \\
\hline 19 & Lahore_B & 31.52064 & 74.40294 & 216.2 & 1961-1990 \\
\hline 20 & Faisalabad & 31.41694 & 73.08338 & 185.6 & 1961-1990 \\
\hline 21 & Rafiqui & 30.76000 & 72.28000 & 150.0 & 1972-1990 \\
\hline 22 & Multan & 30.20141 & 71.43457 & 122.0 & 1961-1990 \\
\hline 23 & Bahawalnagar & 30.00001 & 73.25001 & 161.1 & 1963-1990 \\
\hline 24 & Bahawalpur & 29.38991 & 71.67021 & 110.0 & 1961-1990 \\
\hline 25 & Khanpur & 28.65019 & 70.65043 & 88.4 & 1961-1990 \\
\hline
\end{tabular}

statistics are given in Table 3. As the analysis are made on averaged data, therefore, year to year fluctuations of monthly precipitation are not considered.

Elevation data (Fig. 3) is obtained from void filled seamless SRTM version 3 data freely available from the CGIAR-CSI SRTM 90 m Database: http://srtm.csi.cgiar.org

\subsection{Interpolation methods}

In this paper, different deterministic and geostatistical interpolation techniques have been used to model the PRECIS precipitation data to generate surfaces at higher resolution. Deterministic interpolations use mathematical
Table 3 Summary statistics of 30 years (1961-1990) averaged observed precipitation data in $\mathrm{mm} / \mathrm{month}$

\begin{tabular}{lrrrrrrrr}
\hline Month & Min & Max & Mean & SD & 1st Q & Median & 3rd Q & Q3-Q1 \\
\hline Jan & 3.9 & 111.4 & 43.1 & 35.8 & 11.5 & 33.8 & 76.0 & 64.5 \\
Feb & 5.4 & 172.6 & 63.8 & 52.0 & 20.1 & 43.9 & 103.4 & 83.3 \\
Mar & 5.6 & 242.2 & 88.0 & 66.2 & 34.8 & 78.4 & 142.3 & 107.5 \\
Apr & 2.8 & 167.9 & 58.7 & 48.0 & 19.4 & 46.6 & 100.3 & 80.9 \\
May & 4.0 & 96.7 & 39.2 & 29.2 & 17.2 & 27.9 & 64.3 & 47.1 \\
Jun & 2.8 & 122.6 & 46.2 & 36.1 & 18.3 & 32.9 & 70.4 & 52.0 \\
Jul & 27.5 & 359.4 & 170.7 & 105.9 & 81.2 & 145.8 & 267.0 & 185.8 \\
Aug & 23.0 & 326.3 & 157.6 & 98.3 & 67.7 & 143.0 & 253.8 & 186.2 \\
Sep & 9.3 & 146.5 & 60.0 & 39.4 & 24.6 & 56.7 & 96.9 & 72.3 \\
Oct & 0.6 & 70.2 & 24.3 & 22.7 & 4.8 & 14.0 & 44.7 & 39.9 \\
Nov & 0.7 & 50.7 & 17.1 & 15.8 & 4.0 & 10.9 & 30.9 & 26.9 \\
Dec & 3.0 & 90.7 & 34.8 & 28.5 & 10.4 & 28.9 & 57.7 & 47.3 \\
\hline
\end{tabular}



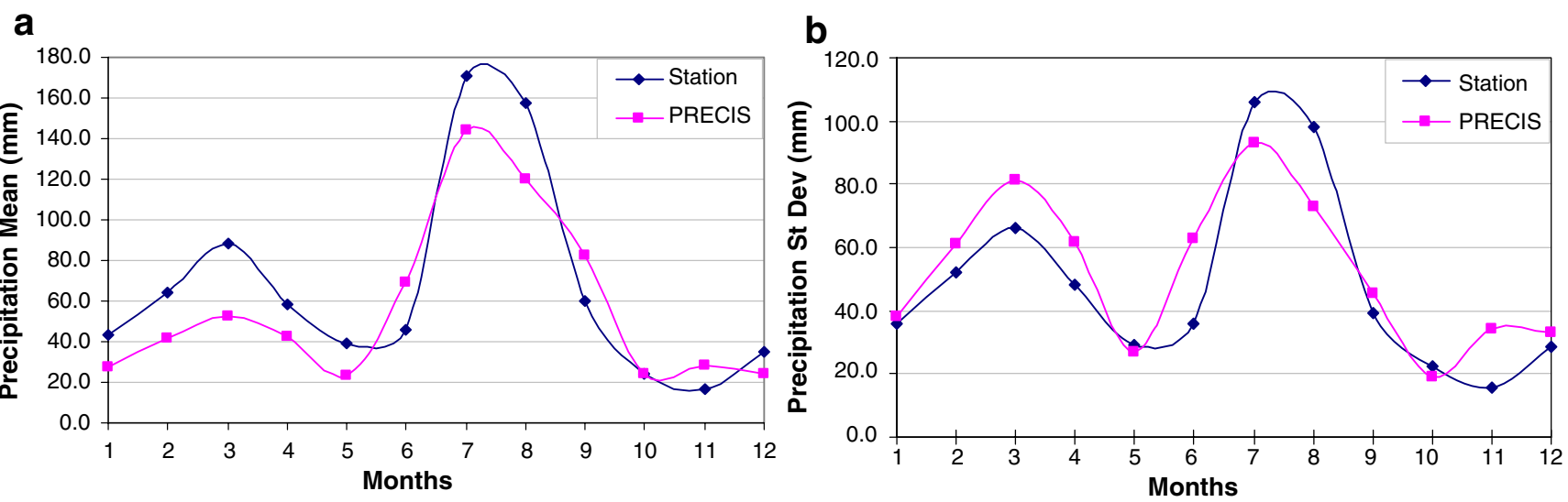

Fig. 4 Scatter plots of observed and modeled a precipitation mean and $\mathbf{b}$ precipitation standard deviation

functions to generate surfaces from the measured points, based on either the extent of similarity or the degree of smoothing (Johnston et al. 2001). Among various deterministic interpolation techniques, inverse distance weighted, local polynomial interpolation, and radial basis functions are used to generate models. These techniques are well described in literature (Hardy 1971; Bouhamidi 2001; Johnston et al. 2001; Hofierka et al. 2002; Lloyd 2005; Zhao et al. 2005; Sarra 2006).

Geostatistic interpolations are based on the theory of regionalized variables and rely on both statistical and mathematical functions. These use a variogram model to describe the spatial continuity of the input data to estimate values at unsampled locations. From this group, ordinary kriging and its multivariate extension ordinary cokriging are used to generate models. Ordinary kriging depends on models of spatial autocorrelation formulated in terms of covariance or semivariogram functions. The main characteristics of these models are sill, range, and nugget. Sill represents the total variation in the data, and range is the distance where autocorrelation vanishes. Nugget effect refers to the situation when sampling locations are close to each other but difference between measurements is not zero. This occurs in semivariogram/covariance model due to either measurement errors or variations at scales too fine to detect. The reader is referred to Isaaks and Srivastava (1989) and Clark and Harper (2000) for basic theory and modeling details. Among various variogram models, only three (spherical, exponential, and rational quadratic) models with the nugget effect are used in this study. Elevation data is used as secondary data (Goovaerts 2000) in ordinary Cokriging models. Models with nugget effect that provide the optimal fit to the semivariance points are selected for further evaluation with observational data.
Table 4 Comparison of cross-validated root mean square prediction errors (RMSE) in $\mathrm{mm} / \mathrm{month}$

\begin{tabular}{|c|c|c|c|c|c|c|c|}
\hline \multirow[t]{2}{*}{ Month } & \multicolumn{4}{|c|}{ Deterministic models } & \multicolumn{3}{|c|}{ Geostatistical models } \\
\hline & IDW & LPI & RBF_swt & RBF_mq & OK_sph & OK_exp & OK_rqd \\
\hline Jan & 15.83 & 15.34 & 15.27 & 15.31 & 15.62 & 15.68 & 15.54 \\
\hline Feb & 24.97 & 24.22 & 24.12 & 24.18 & 24.68 & 24.79 & 24.54 \\
\hline Mar & 31.86 & 30.96 & 30.84 & 30.86 & 31.24 & 31.35 & 31.11 \\
\hline Apr & 24.08 & 24.06 & 23.92 & 23.92 & 23.92 & 23.94 & 23.88 \\
\hline May & 11.25 & 11.23 & 11.03 & 11.45 & 11.49 & 11.48 & 11.44 \\
\hline Jun & 36.68 & 35.91 & 35.62 & 36.15 & 35.41 & 35.89 & 35.31 \\
\hline Jul & 53.54 & 53.75 & 53.32 & 54.4 & 53.38 & 53.68 & 53.29 \\
\hline Aug & 40.45 & 40.65 & 40.37 & 41.18 & 40.41 & 40.46 & 40.41 \\
\hline Sep & 23.74 & 23.58 & 23.53 & 23.55 & 23.51 & 23.47 & 23.45 \\
\hline Oct & 7.84 & 7.97 & 7.91 & 7.81 & 7.89 & 7.92 & 7.88 \\
\hline Nov & 14.45 & 14.27 & 14.26 & 14.27 & 14.37 & 14.47 & 14.32 \\
\hline Dec & 14.41 & 14.00 & 14.00 & 14.04 & 14.26 & 14.39 & 14.16 \\
\hline
\end{tabular}


Fig. 5 Comparison of $r^{2}$ values for two best models for various months

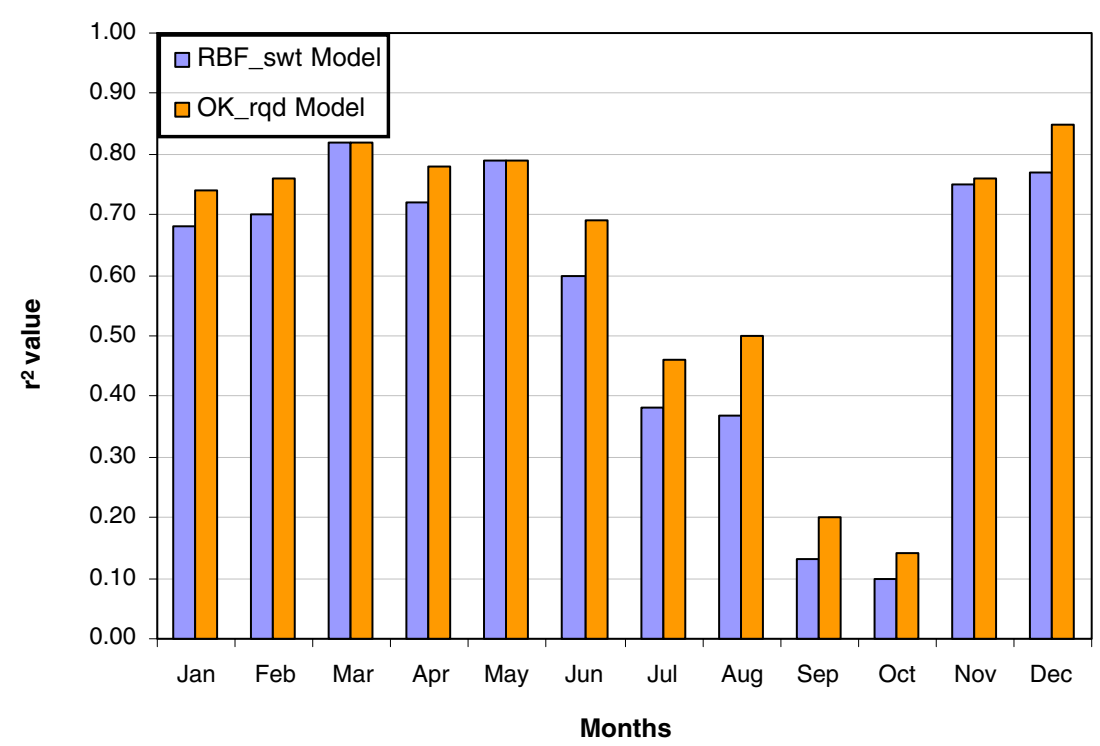

\section{Results and discussions}

\subsection{Quality checking of RCM output}

To check the suitability of the PRECIS simulation output for further interpolation and generation of precipitation surfaces for the study area, station data and PRECIS output are compared (Fig. 4a, b) for mean value and standard deviation derived from the mean monthly precipitation of baseline period. Results show overall good agreement. Pattern of mean precipitation for both data sets is similar during different months except for November and December, and the same is the case with SD. PRECIS overpredicted the mean precipitation during June, September, and November. The maximum difference is during March, whereas minimal is noted for the month of October. Standard deviation of PRECIS data is higher compared to the station data except for the months May, July, August, and October. June is the month with highest difference, whereas May has least difference.

\subsection{Interpolation of PRECIS data}

Initially, seven interpolation models in ArcGIS 9.2 have been used to generate the monthly precipitation surfaces from the PRECIS baseline data. Out of these four models, namely, inverse distance weighted (IDW), local polynomial interpolation (LPI), spline with tension radial basic function (RBF_swt), and multiquadric radial basic function (RBF_mq) belong to the deterministic models, whereas the remaining three models, namely, OK_sph (Ordinary Kriging with Spherical variogram), OK_exp (Ordinary Kriging with Exponential variogram) and OK_rqd (Ordinary Kriging with Rational Quadratic variogram) are geostatistical models. Interpolation model results are compared on the basis of cross-validated root mean squared error (RMSE) of interpolated data. Cross-validated RMSE is the square root of the average of squared differences between the measured and predicted values. This is obtained from calculations repeated for total number of data points' time, while omitting one different data point every time (Wilks 2008). Results are tabulated in Table 4.

Since deterministic and geostatistical modeling are based on different concepts, therefore, both model sets are evaluated separately for their interpolation performance. Overall, the performance of all the models is comparable. However, the best results in the form of least RMSE are from OK_rqd in geostatistical models and from RBF_swt model with exception of the month of October in deterministic models. Interpolation of October is better

Table 5 Cross-validated root mean square prediction errors (RMSE) in $\mathrm{mm} / \mathrm{month}$ of monthly surfaces of precipitation generated by OCK_rqd and OK_rqd models

\begin{tabular}{|c|c|c|c|c|c|c|c|c|c|c|c|c|}
\hline Model & Jan & Feb & Mar & Apr & May & Jun & Jul & Aug & Sep & Oct & Nov & Dec \\
\hline OCK_rqd & 15.49 & 24.29 & 30.61 & 22.91 & 10.85 & 36.49 & 54.98 & 41.33 & 24.17 & 8.02 & 13.97 & 13.98 \\
\hline $\mathrm{OK}$ rqd & 15.54 & 24.54 & 31.11 & 23.88 & 11.44 & 35.31 & 53.29 & 40.41 & 23.45 & 7.88 & 14.32 & 14.16 \\
\hline
\end{tabular}


Fig. 6 Comparison of $r^{2}$ values for Kriging models with and without elevation for various months
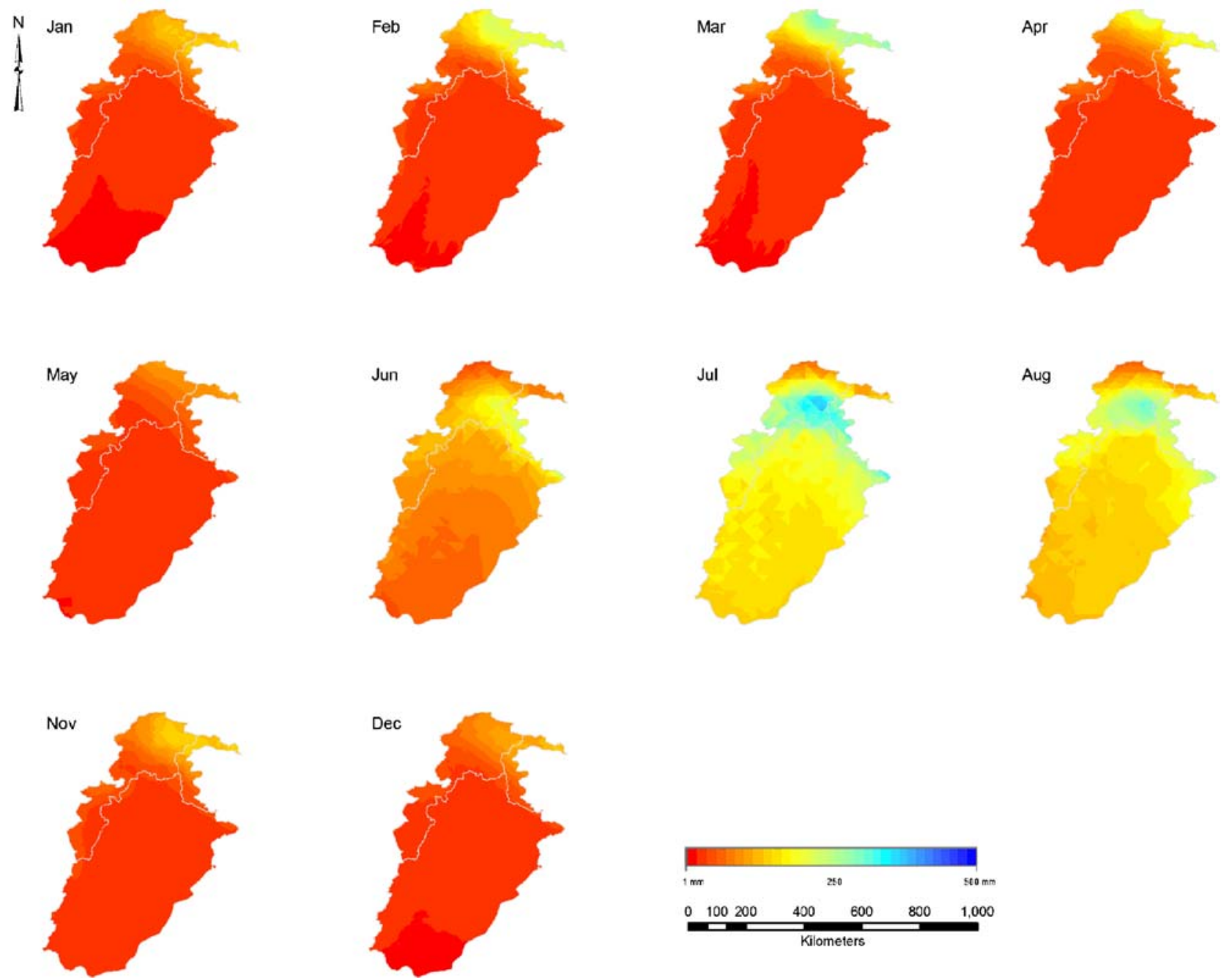

Fig. 7 Monthly precipitation surfaces for baseline period (resolution $250 \mathrm{~m}$ ) 
Fig. 8 Mean precipitations for baseline period (1961-1990) and 2080s (2071-2100) of IPCC future scenarios $\mathrm{A} 2$ and $\mathrm{B} 2$
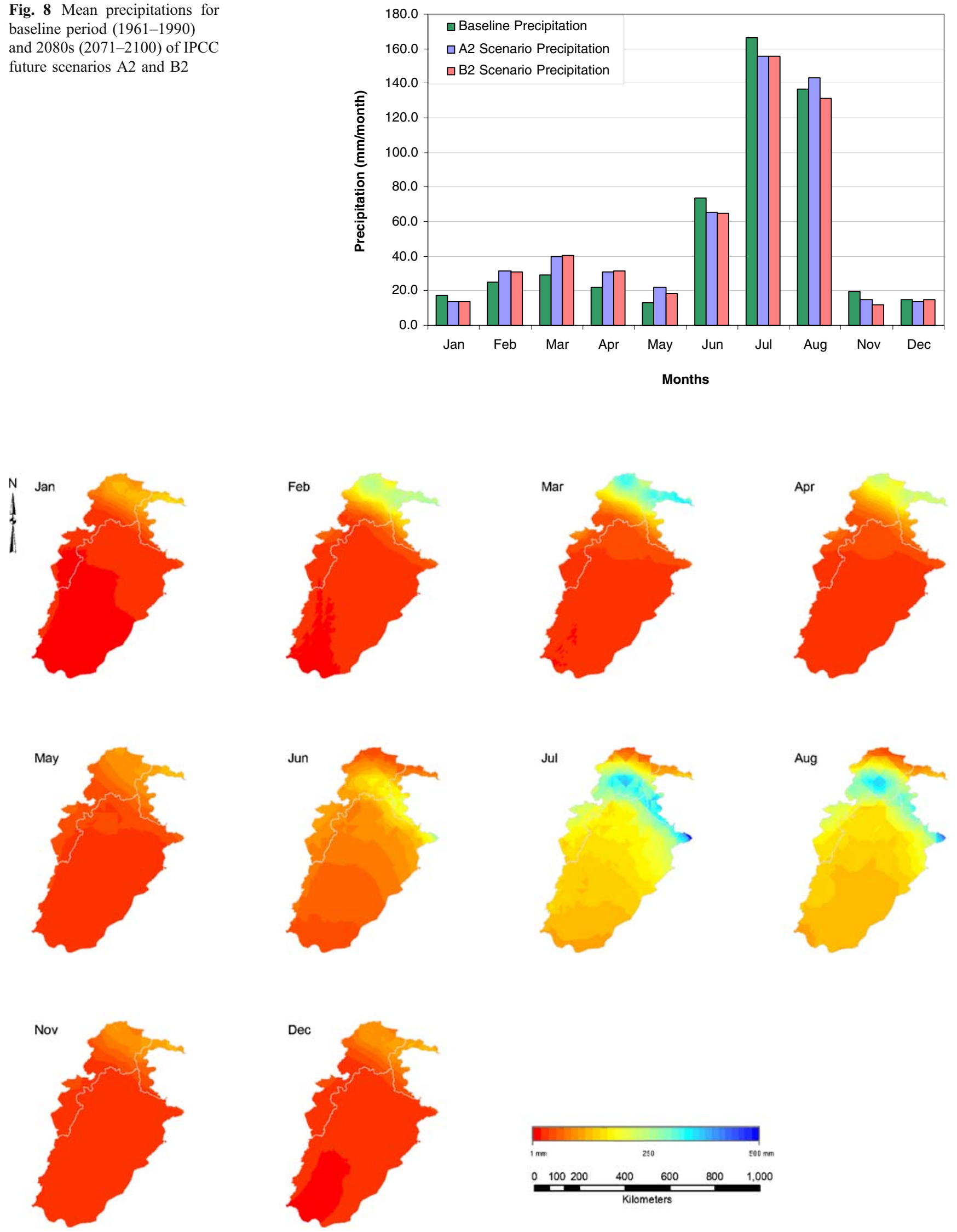
achieved by RBF_mq instead of RBF_swt. This may be attributed to the distribution of data with least standard deviation and minimal difference of third and first quartile among all the months as shown in Table 1. Best model results for monthly surfaces in both model types are then further compared for their performance with validation (observational) data. Modeled mean precipitation values for the location of the climatic stations are compared with the recorded mean precipitation and evaluated with the coefficient of determination $\left(r^{2}\right)$. Results presented in Fig. 5 show that the $r^{2}$ values of OK_rqd (geostatistical model) interpolated surfaces are better than the RBF_swt (deterministic model) for all months which is in accordance with the results of Goovaerts (2000) who also found better performance of geostatistical models for spatial prediction of precipitation. The results for the months from July to October are comparatively poor. Out of these, July and August are the monsoon months with maximum rainfall as shown in Table 3. $r^{2}$ values for these months are 0.46 and 0.50 , respectively. The performance is worst for the months September and October with $r^{2}$ values 0.20 and 0.14 , respectively.

To further investigate the influence of elevation on the spatial and temporal distribution of precipitation, another model OCK_rqd (Ordinary Cokriging with Rationale Quadratic variogram) is applied. In this method, the elevation data from the SRTM is used as secondary variable to generate the monthly surfaces. Selection of final monthly surfaces is based on the same criteria of least cross-validated RMSE values. RMSE values are presented in Table 5.

Months from January to May, November and December show decrease in RMSE whereas months from June to October show increase in RMSE. This increased RMSE for the months June to October is due to weak correlation of PRECIS simulated data with the elevation $\left(r^{2}\right.$ values 0 , $0.08,0.08,0.05$, and 0.09 , respectively). When validated, these monthly interpolated surfaces with the observational
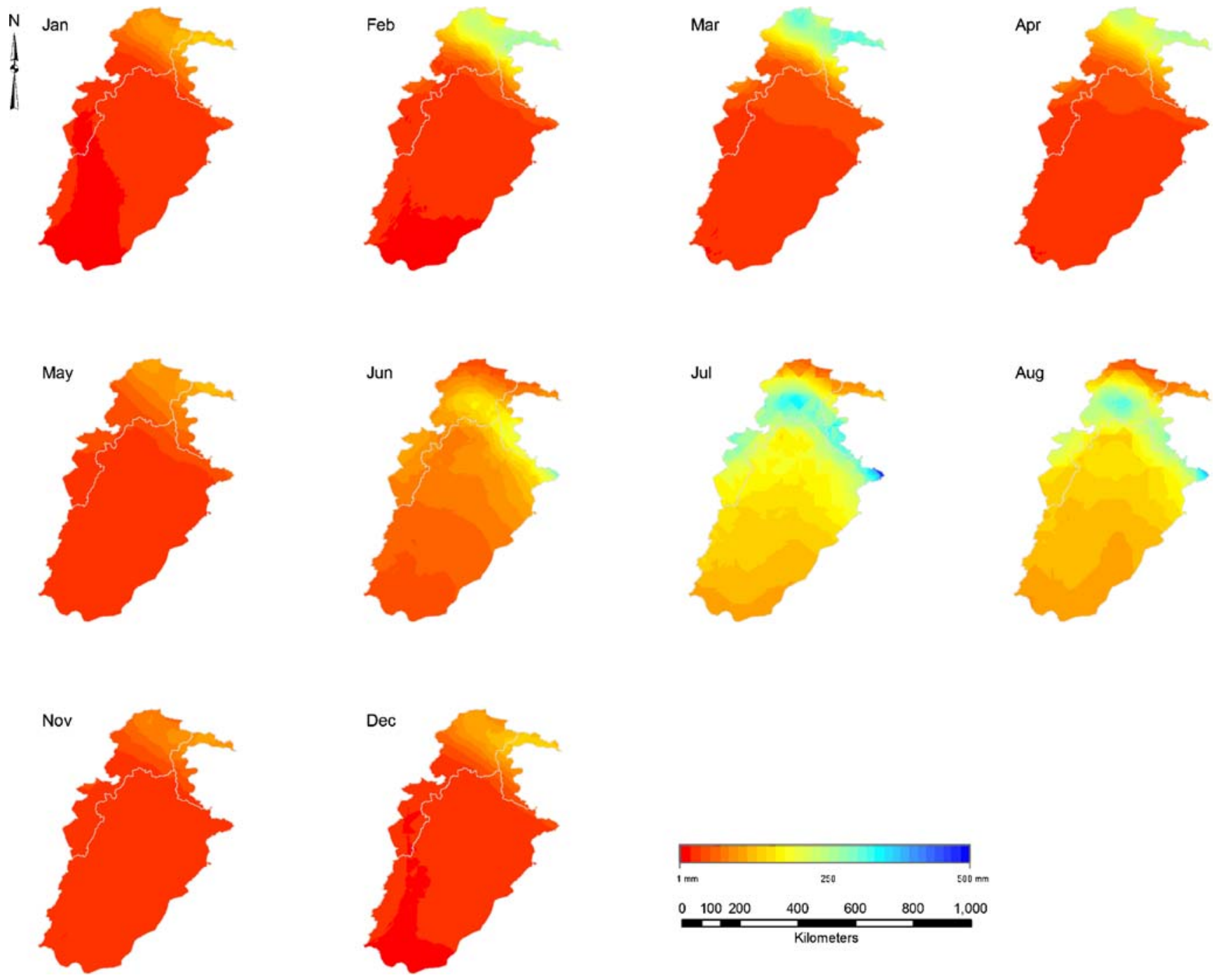

Fig. 10 Monthly precipitation surfaces for 2080s under IPCC B2 scenario 
station data, $r^{2}$ values for the months June to September improved because observational data has reasonable correlation with elevation $\left(r^{2}\right.$ values $0.44,0.25,0.32$, and 0.43 , respectively). Figure 6 shows the increase in $r^{2}$ values from 0.69 to $0.70,0.46$ to $0.49,0.50$ to 0.56 , and 0.20 to 0.25 for the months of June, July, August, and September, respectively, when compared with OK_rqd model. For the rest of the months, there is no significant change in $r^{2}$ values except for the month of October where it drops to 0.11 . Improvement in the results for the monsoon months with the inclusion of elevation data confirms that elevation is an important factor in the distribution of rainfall during this season. This is also in accordance with the results of some studies carried out in different parts of the world (Phillips et al. 1992; Goovaerts 2000; Agnew and Palutikof 2000) that elevation is a strong determinant of climate. The least correlation of the interpolated precipitation with the observations is during the month of October. Detailed
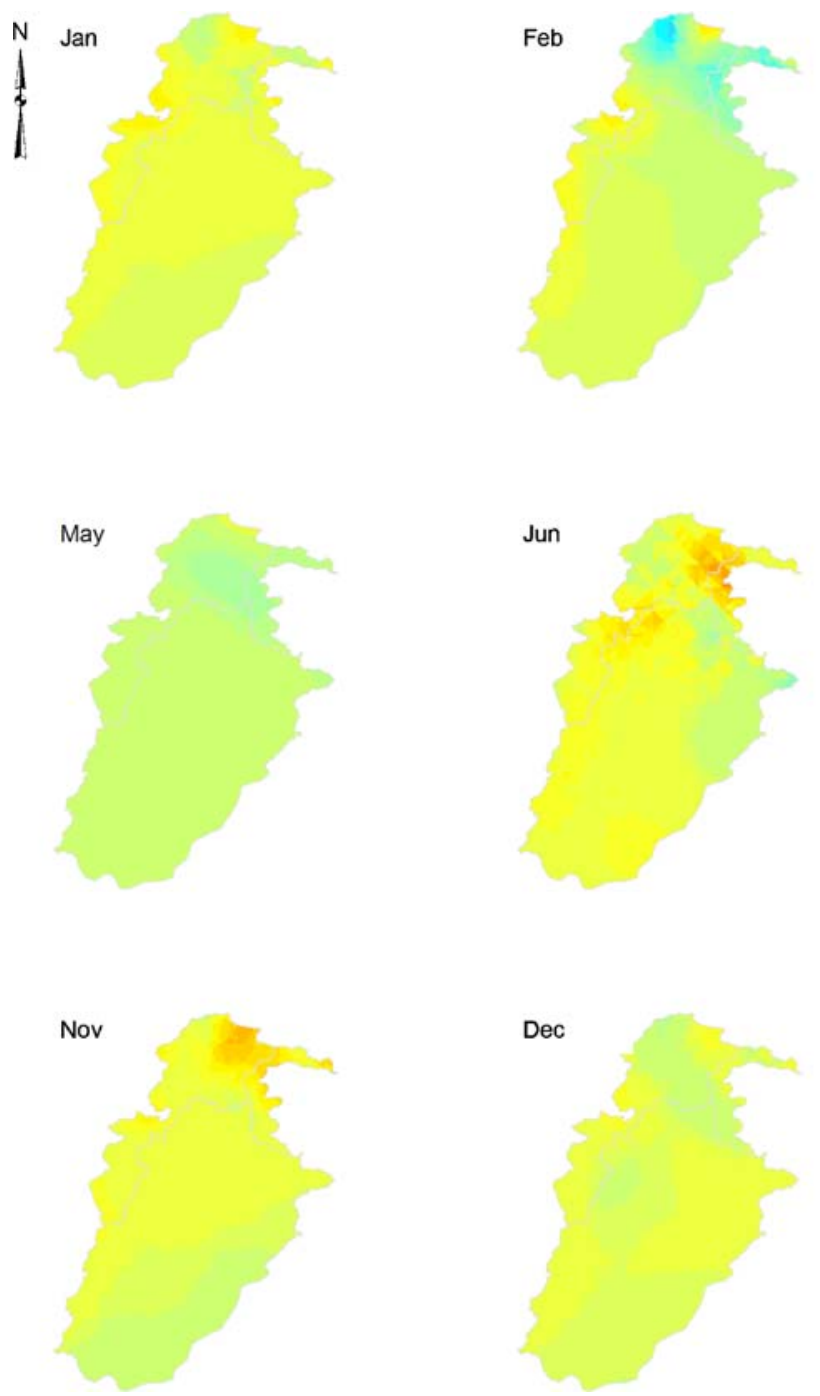

investigation of the data reflects that traces of precipitation with high frequency are reported by the PRECIS, and perhaps, such small quantities are not recorded as significant precipitation at the observational stations. This resulted into weak correlation between both data sets. Poor performance of interpolation methods for the month of September can again be attributed to the limitation of the PRECIS to capture the precipitation pattern.

\subsection{High-resolution baseline precipitation}

Monthly precipitation surfaces for the baseline period except for September and October at a resolution of $250 \mathrm{~m}$ generated by OCK_rqd geostatistical interpolation method are presented in Fig. 7. Spatial pattern of precipitation is similar for the winter (November, December, and January) and spring (February, March, April, and May). It is lowest in the southern parts and increases as we move toward
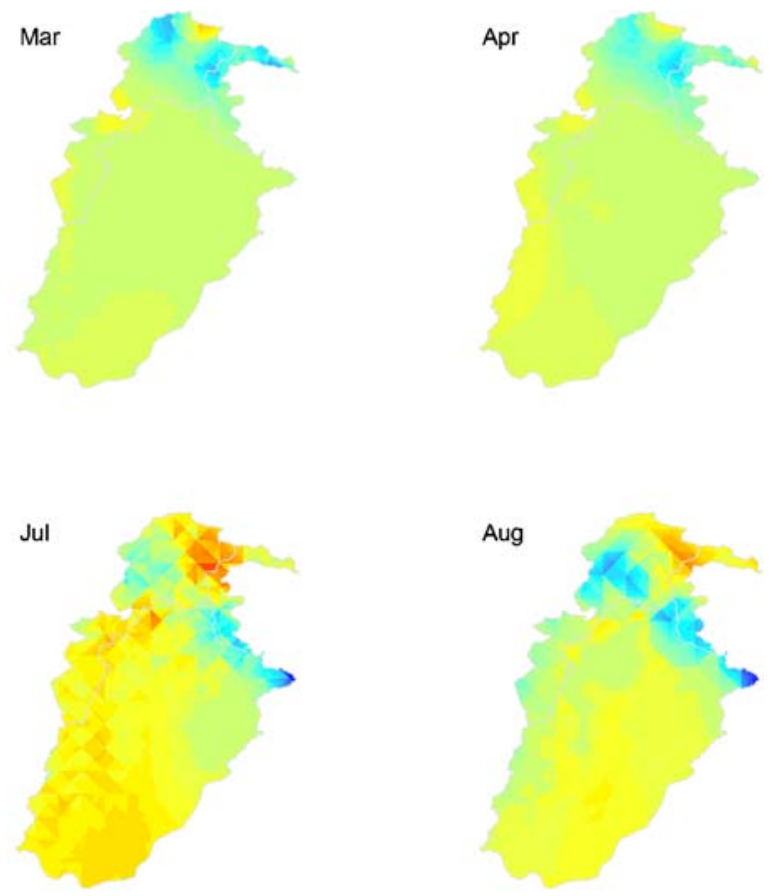

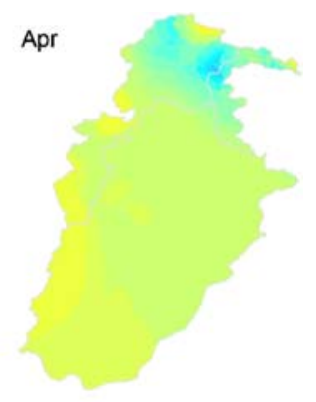


northern areas with the increasing altitude. In contrary, monsoon months (June, July, and August) present a different pattern of precipitation increasing from south toward north, but maximum in southern Himalayan region, and to further north it decreases with the least precipitation in extreme north. This is because of the reason that Himalayan Mountains serve as barriers to the monsoon winds coming from the south and yield maximum rainfall in southern ranges of Himalayas. Northern areas receive precipitation from western cyclonic disturbances originating in the Mediterranean.

\subsection{High-resolution climate change scenario precipitation}

A major caveat in any estimation of climate change is the fact that parameters for modeling are fitted to the current climatic conditions but are not known to remain valid under changed climate. However, it is assumed that if the estimates of a modeling adequately represent the current climate, we can use its climate change estimates with confidence. Based on this assumption, precipitation data of PRECIS for climate change scenarios A2 and B2 for the period 2080 s (20712100 ) is interpolated using the model OCK_rqd to generate surfaces. September and October months are excluded because of their poor results for baseline period. Results are presented in Fig. 8. These indicate decrease in precipitation during winter, increase in spring and monsoon. For August, A2 scenario shows increase in precipitation, whereas B2 scenario shows decrease.

Spatial patterns of 2080s precipitation under A2 and B2 are shown in Figs. 9 and 10. Amount of changes under both scenarios are shown in Figs. 11 and 12. Both future scenarios show almost the same pattern but with varying magnitude of precipitation. In 2080s, northern areas that are under the influence of western cyclonic disturbances, and southern plains will have less precipitation during monsoon,
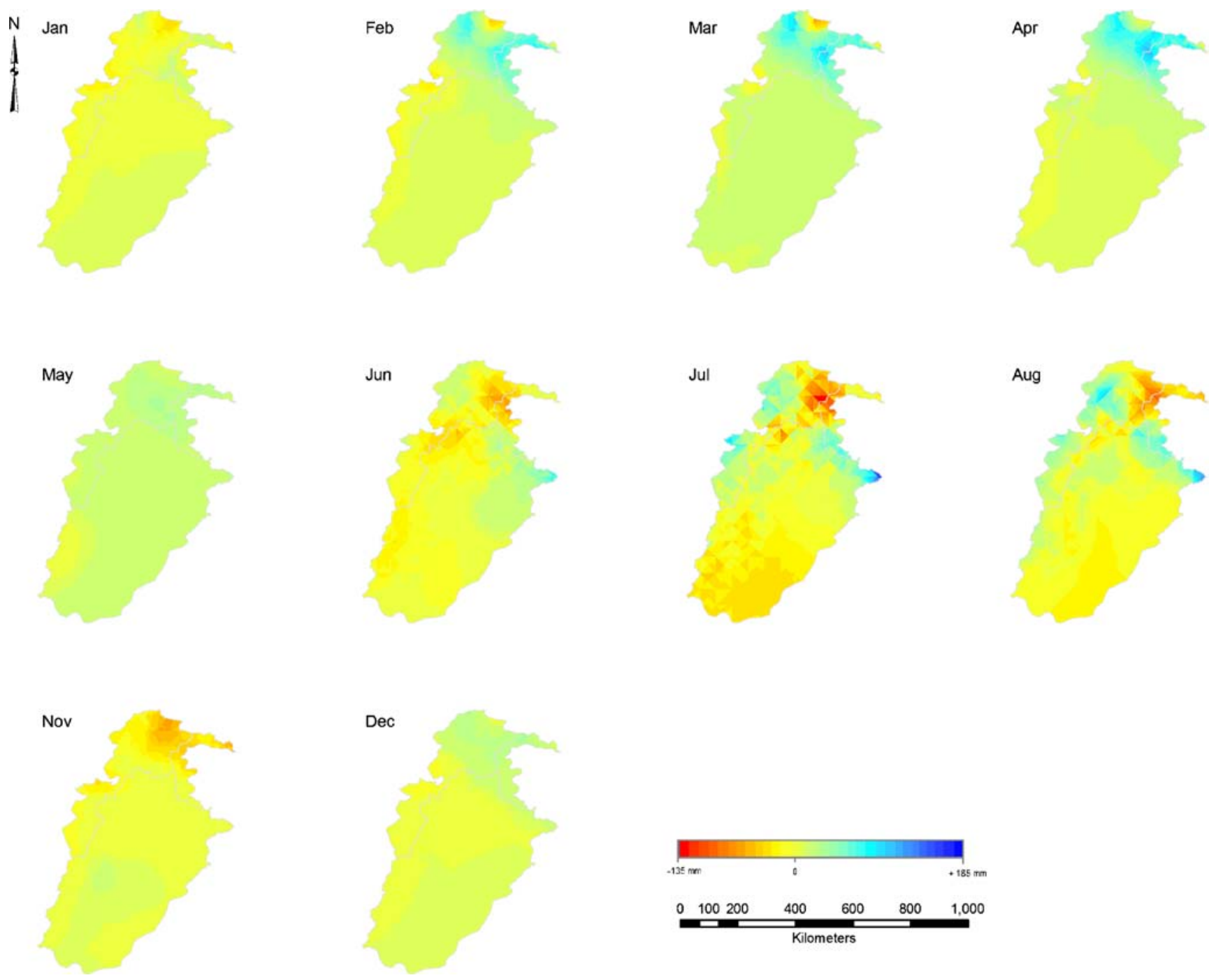

Fig. 12 Monthly precipitation changes for 2080s under IPCC B2 scenario 
whereas Himalayan southern regions will have more precipitation. Overall western and southwestern areas will receive less precipitation throughout the year except for peak monsoon months.

Further, results of $t$ test at $95 \%$ confidence interval show that changes in precipitation over the study area are significant for all months except July, August, and December. $P$ values for these months are $0.170,0.450$, 0.494 (under A2 scenario) and 0.140, 0.248, 0.131 (under B2 scenario), respectively.

\section{Conclusion}

Among important climatic variables, precipitation is difficult to represent due to high inherent variability in its spatial and temporal patterns. It is even more difficult in the study area in which different mechanisms are responsible for its occurrence. In this paper, PRECIS-RCM-generated precipitation surfaces are evaluated with the observational data and further downscaled for more detailed regional information $(250 \mathrm{~m} \times 250 \mathrm{~m})$ to further conduct climate change impact assessments in various sectors. Although the results have associated uncertainties, these provide good evidence that (1) PRECIS capture pattern of current precipitation for most of months; (2) the usefulness of GIS-based interpolation technique (Ordinary Cokriging) for the fine-scale spatial interpolation precipitation; and (3) patterns of precipitation vary temporally and spatially significantly at small scale.

It is also noted that the systematic errors of RCM or driving GCM cannot be improved by the interpolation techniques used. This is the case with the months of September and October precipitation that need to be improved in RCM simulations for the study area. This methodology can also be applied for the fine-scale spatial distribution of other climatic variables such as temperature in the study area.

Acknowledgement The present study is a part of the research funded by Higher Education Commission of Pakistan (PIN no. 041 221461B-057) and also supported by National Natural Science Foundation of China (nos. 40671067 and 30770387). Authors are thankful to Nasir Ahmed (PU), Sally Aitken (UBC) and Tongli Wang (UBC) to facilitate this research and improve the manuscript. Thanks are also due to Pakistan Meteorological Department and CGIARConsortium for Spatial Information for making the data available for this study. We also gratefully acknowledge the anonymous reviewers for critical reviews of the manuscript.

\section{References}

Agnew MD, Palutikof JP (2000) GIS based construction of baseline climatologies for the Mediterranean using terrain variables. Clim Res 14:115-127
Akhtar M, Ahmad N, Booij MJ (2008) Use of regional climate model simulations as input for hydrological models for the HindukushKarakorum-Himalaya region. Hydrology and Earth System Sciences Discussions 5:865-902

Bouhamidi A (2001) Hilbertian approach for univariate spline with tension. Approx Theory its Appl 17(4):36-57

Bowling LC, Lettenmaier DP, Nijssen B, Graham LP, Clark DB, Maayar ME, Essery R, Goers S, Habets F, Bvd H, Jin J, Kahan D, Lohmann D, Mahanama S, Mocko D, Nasonova O, Samuelsson P, Shmakin AB, Takata K, Verseghy D, Viterbo P, Xia Y, Ma X, Xue Y, Yang ZL (2003) Simulation of high latitude hydrological processes in the Torne-Kalix basin: PILPS Phase 2 (e): 1. Experiment description and summary intercomparisons. Glob Planet Change 38(1-2):1-30

Brunsdon C, McClatchey J, Unwin DJ (2001) Spatial variations in the average rainfall-altitude relationship in Great Britain: an approach using geographically weighted regression. Int J Climatol 21:455-466

Busuioc A, Chen D, Hellström C (2001) Performance of statistical downscaling models in GCM validation and regional climate change estimates: application for Swedish precipitation. Int J Climatol 21:557-578

Charles SP, Bates BC, Whetton PH, Hughes JP (1999) Validation of downscaling models for changed climate conditions: case study of southwestern Australia. Clim Res 12:1-14

Ciret C, Sellers AH (1998) Sensitivity of ecosystem models to the spatial resolution of the NCAR Community Climate Model CCM2. Clim Dyn 14:409-429

Clark I, Harper WV (2000) Practical geostatistics 2000. Ecosse North America Llc, Columbus, $\mathrm{OH}$

Dirks KN, Hay JE, Stow CD, Harris D (1998) High-resolution studies of rainfall on Norfolk Island Part II: interpolation of rainfall data. J Hydrol 208(3-4):187-193

Fuentes U, Heimann D (2000) An improved statistical-dynamical downscaling scheme and its application to the alpine precipitation climatology. Theor Appl Climatol 65:119-135

Gaffin S, Xing X, Yetman G (2004) Downscaling and geo-spatial gridding of socio-economic projections from the IPCC Special Report on Emissions Scenarios (SRES). Glob Environ Change 14(2):105-123

Giorgi F (1990) Simulation of regional climate using a limited area model nested in a general circulation model. J Clim 3:941-963

Giorgi F, Mearns L (1991) Approaches to the simulation of regional climate change: a review. Review of Geophysics 29:191-216

Goovaerts P (2000) Geostatistical approaches for incorporating elevation into the spatial interpolation of rainfall. J Hydrol 228:113-129

Gordon CC, Cooper C, Senior CA, Banks H, Gregory JM, Mitchell JFB, Wood RA (2000) The simulation of SST, sea ice extents and ocean heat transport in a version of the Hadley centre coupled model without flux adjustment. Clim Dyn 16(2-3):1147-1168

Grotch SL, MacCracken MC (1991) The use of general circulation models to predict regional climate change. J Clim 4:286-303

Hardy RL (1971) Multiquadratic equations of topography and other irregular surfaces. J Geophys Res 76(8):1905-1915

Hellström C, Chen D (2003) Statistical downscaling based on dynamically downscaled predictors: application to monthly precipitation in Sweden. Adv Atmos Sci 20(6):951-958

Hofierka J, Parajka J, Mitasova H, Mitas L (2002) Multivariate interpolation of precipitation using regularized spline with tension. Trans GIS 6(2):135-150

Isaaks EH, Srivastava RM (1989) An introduction to applied geostatistics. Oxford University Press, New York

Johnston K, VerHoef JM, Krivoruchko K, Lucas N (2001) Using ArcGIS Geostatistical Analyst- GIS by ESRI, United States of America

Jones TC, Gregory JM, Ingram WJ, Johnson CE, Jones A, Lowe JA, Mithcell JFB, Roberts DL, Sexton DMH, Stevenson DS, Tett 
SFB, Woodage MJ (2003) Anthropogenic climate change for 1860-2100 simulated with the HadCM3 model under updated emissions scenarios. Clim Dyn 20:583-612

Karl TR, Wang WC, Schlesinger ME, Knight RW, Portman D (1990) A method of relating general circulation model simulated climate to observed local climate. Part I: Seasonal statistics. J Climate 3:1053-1079

Li X, Sailor D (2000) Application of tree structured regression for regional precipitation prediction using general circulation model output. Clim Res 16:17-30

Linderson ML, Achberger C, Chen D (2004) Statistical downscaling and scenario construction of precipitation in Scania, southern Sweden. Nord Hydrol 35(3):261-287

Lloyd CD (2005) Assessing the effect of integrating elevation data into the estimation of monthly precipitation in Great Britain. J Hydrol 308B:128-150

Murphy J (1999) An evaluation of statistical and dynamical techniques for downscaling local climate. J Clim 12(8):2256-2284

Nijssen B, Bowling LC, Lettenmaier DP, Clark DB, Maayar ME, Essery R, Goers S, Gusev YM, Habets F, Hurk BVD, Jin J, Kahan D, Lohmann D, Ma X, Mahanama S, Mocko D, Nasonova O, Niu GY, Samuelsson P, Shmakin AB, Takata K, Verseghy D, Viterbo P, Xia Y, Xue Y, Yang ZL (2003) Simulation of high latitude hydrological processes in the Torne-Kalix basin: PILPS Phase 2(e): 2: Comparison of model results with observations. Global Planet Change 38(1-2):31-53

Phillips DL, Dolph J, Marks D (1992) A comparison of geostatistical procedures for spatial analysis of precipitation in mountainous terrain. Agriculture and Forest Meteorology 58:119-141

Price DT, McKenney DW, Nalder IA, Hutchinson MF, Kesteven JL (2000) A comparison of two statistical methods for spatial interpolation of Canadian monthly mean climate data. Agric For Meteorol 101:81-94

Sarra SA (2006) Integrated multiquadric radial basis function approximation methods. ComputMath Appl 51(8):1283-1296
Tabios GQ, Salas JD (1985) A comparative analysis of techniques for spatial interpolation of precipitation. Water Resource Bulletin 21 (3):365-380

Thiessen AH (1911) Precipitation averages for large areas. Mon Weather Rev 39(7):1082-1084

vanVuuren DP, Lucas PL, Hilderink H (2007) Downscaling drivers of global environmental change: Enabling use of global SRES scenarios at the national and grid levels. Glob Environ Change $17: 114-130$

vonStorch H (1999) The global and regional climate system. In: vonStorch H, Flöser G (eds) Anthropogenic climate change. Springer Verlag, Berlin, pp 3-36

vonStorch H, Zorita E, Cubash U (1993) Downscaling of global climate change estimates to regional scales: an application to Iberian rainfall in wintertime. J Clim 6:1161-1671

Wilks DS (2008) High-resolution spatial interpolation of weather generator parameters using local weighted regressions. Agric For Meteorol 148:111-120

Wilson S, Hassell D, Hein D, Jones R, Taylor R (2005) Installing and using the Hadley Centre regional climate modelling system, PRECIS (version 1.4), Met Office Hadley Centre, Exeter, UK

Xu CY (1999) From GCMs to river flow: a review of downscaling methods and hydrologic modelling approaches. Prog Phys Geogr 23(2):229-249

Yarnal B, Comrie CC, Frakes B, Brown P (2001) Developments and prospects in synoptic climatology. Int J Climatol 21:19231950

Zhao C, Nan Z, Cheng G (2005) Methods for modelling of temporal and spatial distribution of air temperature at landscape scale in southern Qilian mountains, China. Ecolo Model 189:209-220

Zorita E, vonStorch H (1999) The analog method as a simple statistical downscaling technique: comparison with more complicated methods. J Clim 12(8):2474-2489 